\title{
Bone mineral density, osteopenia, osteoporosis, and fracture risk in patients with atopic dermatitis: a systematic review and meta- analysis
}

\author{
Di Wu ${ }^{1 \#}$, Xiang-Dong Wu ${ }^{1 \#}$, Xi Zhou ${ }^{1}$, Wei Huang ${ }^{2}$, Changqi Luo ${ }^{3}$, Yong Liu ${ }^{1}$ \\ ${ }^{1}$ Department of Orthopaedic Surgery, Peking Union Medical College Hospital, Chinese Academy of Medical Sciences \& Peking Union Medical \\ College, Beijing, China; ${ }^{2}$ Department of Orthopaedic Surgery, The First Affiliated Hospital of Chongqing Medical University, Chongqing, China; \\ ${ }^{3}$ Department of Orthopaedic Surgery, The Second People's Hospital of Yibin, Yibin, China \\ Contributions: (I) Conception and design: D Wu, XD Wu, Y Liu, W Huang; (II) Administrative support: Y Liu; (III) Provision of study materials or \\ patients: All authors; (IV) Collection and assembly of data: XD Wu, D Wu, X Zhou, C Luo; (V) Data analysis and interpretation: All authors; (VI) \\ Manuscript writing: All authors; (VII) Final approval of manuscript: All authors. \\ \#These authors contributed equally to this work. \\ Correspondence to: Yong Liu, MD, PhD. Department of Orthopaedic Surgery, Peking Union Medical College Hospital, Chinese Academy \\ of Medical Sciences \& Peking Union Medical College, No. 1 Shuaifuyuan Road, Wangfujing, Dongcheng District, Beijing 100730, China. \\ Email: liuysubmission@126.com.
}

Background: The relationship between atopic dermatitis (AD) and abnormal bone metabolism remains unclear. We performed a systematic review and meta-analysis to determine whether patients with $\mathrm{AD}$ were associated with increased risks of low bone mineral density (BMD), osteopenia, osteoporosis, and related fractures.

Methods: We searched PubMed, Embase, and the Cochrane Library through December 2019 to identify studies that investigated the association between $\mathrm{AD}$ and abnormal bone metabolism (including BMD, osteopenia, osteoporosis, and related fractures). The predefined primary outcome was related fractures; secondary outcomes included osteoporosis, osteopenia, and BMD. We calculated the summary odds ratios (ORs) and 95\% confidence intervals (CIs) using a random-effects model.

Results: Ten studies were included in this systematic review. In children and adolescents, four studies investigated the association between $\mathrm{AD}$ and $\mathrm{BMD}$; three studies indicated that children and adolescents with $\mathrm{AD}$ were associated with an increased risk of low BMD; one study found similar BMD between $\mathrm{AD}$ and control groups. In adults, three studies assessed the risk of fracture and were included in the meta-analysis, comprising 562,405 $\mathrm{AD}$ patients among 3,171,268 participants. Adults with $\mathrm{AD}$ were associated with an increased risk of fracture (OR 1.13; 95\% CI, 1.05-1.22; $\mathrm{P}=0.001$ ). Three studies investigated the association between $\mathrm{AD}$ and osteoporosis, which suggested that patients with $\mathrm{AD}$ were associated with an increased risk of osteoporosis (OR 1.95; 95\% CI, 1.18-3.23; $\mathrm{P}=0.009)$. Further, patients with AD were associated with increased risks of osteopenia (OR 1.90; 95\% CI, 1.51-2.38; $\mathrm{P}<0.001$ ) and low BMD at the femur and spine.

Conclusions: Patients with $\mathrm{AD}$ were associated with increased risks of low $\mathrm{BMD}$, osteopenia, osteoporosis, and related fractures. Both clinical studies and basic research are needed to clarify the mechanisms of association between $\mathrm{AD}$ and abnormal bone metabolism.

Keywords: Atopic dermatitis (AD); bone mineral density (BMD); osteopenia; osteoporosis; fracture

Submitted Jun 14, 2020. Accepted for publication Sep 29, 2020.

doi: $10.21037 / \mathrm{atm}-20-4708$

View this article at: http://dx.doi.org/10.21037/atm-20-4708 


\section{Introduction}

Atopic dermatitis (AD) is a common chronic, pruritic inflammatory skin disease, which afflicts not only 10 $20 \%$ of children and adolescents, but also $2-10 \%$ adults around the world (1-4). With an increasing prevalence of $\mathrm{AD}$ and its manifestation in developed and developing countries, together with more supporting evidence of the progression to other long-term sequelae, $\mathrm{AD}$ has developed into a worldwide public health problem and burden.

During the past years, there is growing evidence that suggests that people who suffer from $\mathrm{AD}$ are more likely to have a lower bone mineral density (BMD), higher prevalence of osteopenia, osteoporosis, and related fractures when compared with those without AD (5-9). However, evidence of the potential association between $\mathrm{AD}$ and abnormalities in the bone mineral metabolism remains fragmented (10-14). As osteoporosis and fracture are associated with increased morbidity and mortality, which also represents a significant public health challenge, a better understanding of the relationship between $\mathrm{AD}$ and abnormal bone metabolism would help to clarify this issue and intervene earlier, if needed.

To date, several previous studies have evaluated the abnormalities in bone mineral metabolism with disease progression in $\mathrm{AD}$ patients. However, they have reported inconsistent results, and a comprehensive review and analysis of the existing evidence to elaborate on the relation between $\mathrm{AD}$ and abnormal bone metabolism is lacking. In order to clarify this issue, we performed this systematic review and meta-analysis, aiming to integrate the growing body of evidence, clarify the association between $\mathrm{AD}$ and abnormal bone metabolism, and to provide direction for future research in this domain. We present the following article in accordance with the PRISMA reporting checklist (available at http://dx.doi. org/10.21037/atm-20-4708).

\section{Methods}

\section{Study design}

This systematic review and meta-analysis were conducted following the Cochrane Handbook for Systematic Reviews of Interventions and reported according to the PRISMA (Preferred Reporting Items for Systematic Reviews and Meta-Analyses) checklist $(15,16)$.

\section{Search strategy}

We systematically searched PubMed, Embase, and the Cochrane Library from inception to December 2019. The exploded Medical Subject Heading (MeSH) terms and corresponding keywords were used in the electronic searches (MeSH exp "Dermatitis, Atopic", "Eczema", and keywords "Atopic dermatitis", "Eczema") and (MeSH exp"Bone Density", "Bone Diseases, Metabolic", "Osteoporosis", "Fractures, Bone" and keywords "Bone mineral density", "Osteopenia", "Osteoporosis", "Fracture"). Details of the search strategy are available in Table S1. We also searched unpublished studies and ClinicalTrials.gov registry (https:// clinicaltrials.gov/), and manually checked the reference lists of included studies and related reviews to identify any potentially eligible articles. No language restriction was imposed. In addition, we also tried to contact the authors for detailed information of primary studies. The obtained study records were exported from medical databases and imported into a software package (EndNote, version X8; Thomson Reuters) for records management.

\section{Eligibility criteria}

We included any observational studies (e.g., cohort, casecontrol, and cross-sectional studies) that investigated and reported a risk estimate for the abnormal bone metabolism (including BMD, osteopenia, osteoporosis, and related fractures) in patients with $\mathrm{AD}$ compared with a control group (e.g., patients without $\mathrm{AD}$ or general population). Notably, there was no limitation on age or disease duration. The predefined primary outcome measure was a fracture. Secondary outcomes included osteoporosis, osteopenia, and BMD.

\section{Study selection}

Two authors independently undertook electronic searches, removed the duplicated records, and screened the titles and abstracts for potentially eligible studies. The full-text articles were accessed and reviewed to identify eligibility. Selection discrepancies were resolved by discussion and involvement of a third reviewer, if necessary.

\section{Data collection}

The following items were extracted from the included 
studies: first author, publication year, study location, study design, study period, AD identification, sample size, patient characteristics, covariates used in adjustment model, and multivariate-adjusted risk estimates for the association between $\mathrm{AD}$ and abnormal bone metabolism. Extracted data were entered into a predefined standardized Excel (Microsoft Corporation, WA, USA) file. The supplementary files of the included studies were also examined for data extraction, and corresponding authors were contacted to verify the extracted data or request the missing data. Data extraction was performed by one author and confirmed independently by another two authors.

\section{Quality assessment}

Two authors assessed the risk of bias of included studies. The quality of the included cohort study or case-control study was evaluated using the Newcastle-Ottawa Scale (NOS), which is a validated assessment tool for the quality of non-randomized studies in meta-analyses (17). This scale allocates a maximum of nine stars to comprises three domains (selection of participants and measurement of exposure, comparability outcomes, adequacy of followup) through which bias might be introduced. Studies were categorized as low (score 0-3), moderate (score 4-6), or high quality (score 7-9). The quality of included cross-sectional study was evaluated using the Agency for Healthcare Research and Quality (AHRQ), which is a validated assessment tool that includes an 11-item questionnaire to explore the quality of patient recruitment, outcome measurement, blinding of the observers and follow-up of patients. Each item of the checklist was scored with "Yes", "No", or "Unclear" $(18,19)$. Any discrepancy was resolved by discussion and consensus, with the opinion of a third reviewer sought where necessary. Poor study quality was not an exclusion criterion.

\section{Statistics analysis}

The risk estimates for osteopenia, osteoporosis, and related fracture incidence observed in studies were weighted using the inverse variance method, and pooled using the DerSimonian and Laird random-effects model to produce odds ratios (ORs) with 95\% confidence intervals (CIs). Heterogeneity was assessed by using the Cochran Q statistic, a two-sided $\mathrm{P}<0.05$ was considered statistically significant. Heterogeneity was also quantified using the $\mathrm{I}^{2}$ statistic, $\mathrm{I}^{2}$ values of $0 \%, 25 \%, 50 \%$, and $75 \%$ indicate no, low, moderate, and high heterogeneity, respectively (20). Publication bias was assessed using Egger's regression test (21). A P value $<0.05$ was considered statistically significant, except where otherwise specified. Data analysis was conducted using Stata software, version 13.0 (Stata Corporation, College Station, TX, USA).

\section{Results}

\section{Study selection}

The PRISMA flow diagram of study selection is shown in Figure 1. A total of 1,109 potentially relevant records were identified through the initial electronic search, and six additional records were identified through other sources. After removing duplicates, 963 records remained, and 943 records were further excluded after reviewing their titles and abstracts. The full texts of the remaining 20 records were carefully scrutinized for eligibility, and ten studies met the inclusion criteria and were included in the qualitative synthesis (5-14).

\section{Study characteristics and risk of bias assessment}

The main characteristics of the included studies are presented in Table 1, and more details are shown in Table S2. Of the ten included studies, seven were cross-sectional studies and three were retrospective cohort studies; four studies recruited children and adolescents and six studies reporting on adult patients. These ten studies were published between 1997 and 2019. More than half of the studies are from North America and Europe, and the others are from Asia, South America, and Australia. The number of participants in these studies ranged from 29 to $61,065,660$.

The quality of the included studies is shown in Tables S3,S4. The average NOS score was 7.5, and the score for all cohort studies was 7 or above, which suggested that all the studies were of high quality, while the general quality of the cross-sectional studies was poor, but most of the cross-sectional studies were not included in the metaanalysis.

\section{Children and adolescents}

Four studies, including 3,436 participants, investigated the $\mathrm{BMD}$ changes in children and adolescents with $\mathrm{AD}$ (4-8). Three studies measured lumbar and femur using dual-energy X-ray absorptiometry (DEXA) and found that 


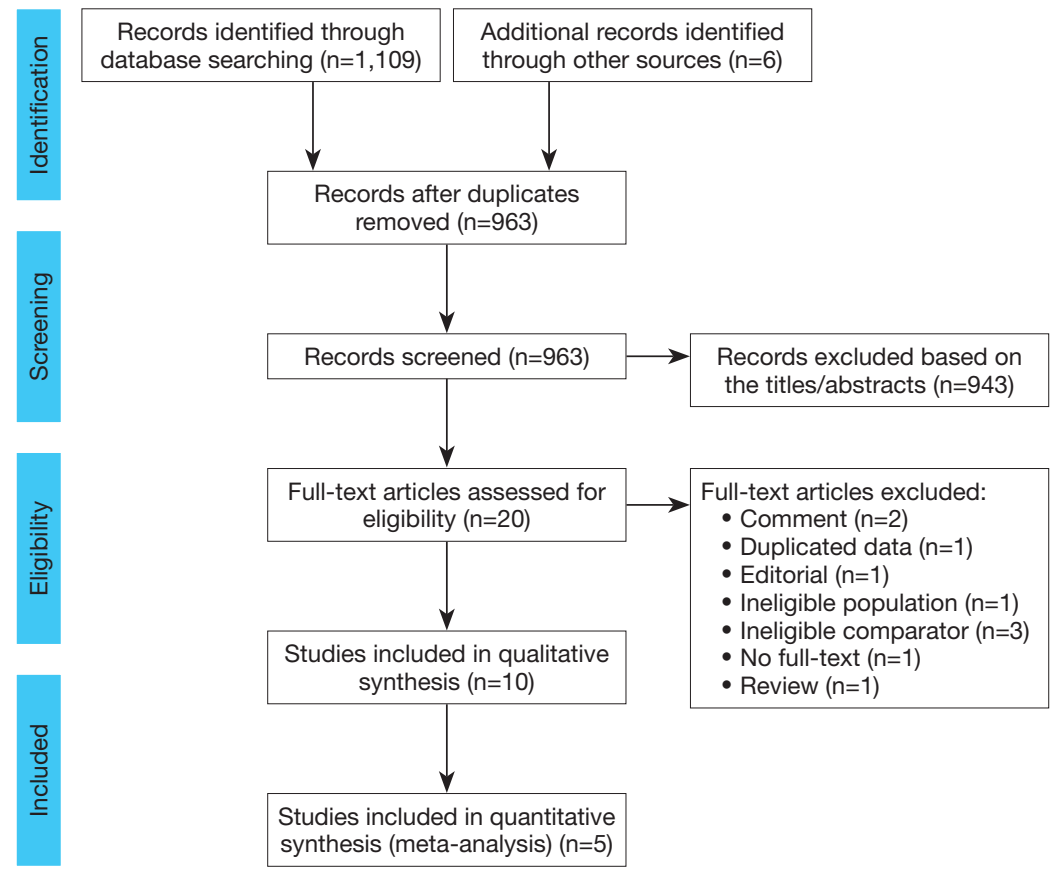

Figure 1 Flow diagram showing the process of literature screening, study selection, and reasons for exclusion.

children and adolescents who were diagnosed with $\mathrm{AD}$ had a higher rate of lower BMD (Z-score). In contrast, one study measured radius and tibia using quantitative ultrasound bone sonometry (QUBS) and detected similar $\mathrm{BMD}$ (Z-score) between $\mathrm{AD}$ and control groups.

\section{Adults}

Three studies evaluated the risk of fracture and were included in the meta-analysis, comprising 562,405 AD patients among 3,171,268 participants (11-13). Compared with patients without $\mathrm{AD}$, patients with $\mathrm{AD}$ were at a higher risk of fracture (OR 1.13; 95\% CI, 1.05-1.22; $\mathrm{P}=0.001)$, and there was high heterogeneity $\left(\mathrm{I}^{2}=79.9 \%\right.$; $\mathrm{P}<0.001)$ (Figure 2). Three studies involving 105,566,867 participants were included in the meta-analysis of $\mathrm{AD}$ and osteoporosis $(11,12,14)$. Patients with $\mathrm{AD}$ were associated with an increased risk of osteoporosis (OR 1.95; 95\% CI, $1.18-3.23 ; \mathrm{P}=0.009)$ when compared with those without $\mathrm{AD}$ (Figure 3). Similarly, patients with $\mathrm{AD}$ were associated with an increased risk of osteopenia (OR 1.90; 95\% CI, 1.512.38; $\mathrm{P}<0.001)$ (Figure 4). In addition, patients with $\mathrm{AD}$ were also associated with decreased BMD (Z-score) at the femur and spine.

\section{Publication bias}

For the primary outcome, publication bias was indicated by the Egger regression asymmetry test $(\mathrm{P}=0.028)$, which might be derived from the limited amount of included studies.

\section{Discussion}

\section{Main findings}

To our knowledge, this is the first systematic review and meta-analysis that comprehensively reviewed the currently available evidence to investigate the association between $\mathrm{AD}$ and abnormal bone metabolism. However, there is still a lack of high-quality evidence for a comprehensive assessment. We found that children and adolescents with $\mathrm{AD}$ were associated with diminished $\mathrm{BMD}$, and this effect may be accumulated and aggravated in adult patients, who suffered from $\mathrm{AD}$ were associated with increased risks of low BMD, osteopenia, osteoporosis, and related fractures.

\section{Possible mechanisms}

The mechanisms that predispose $\mathrm{AD}$ patients to low 


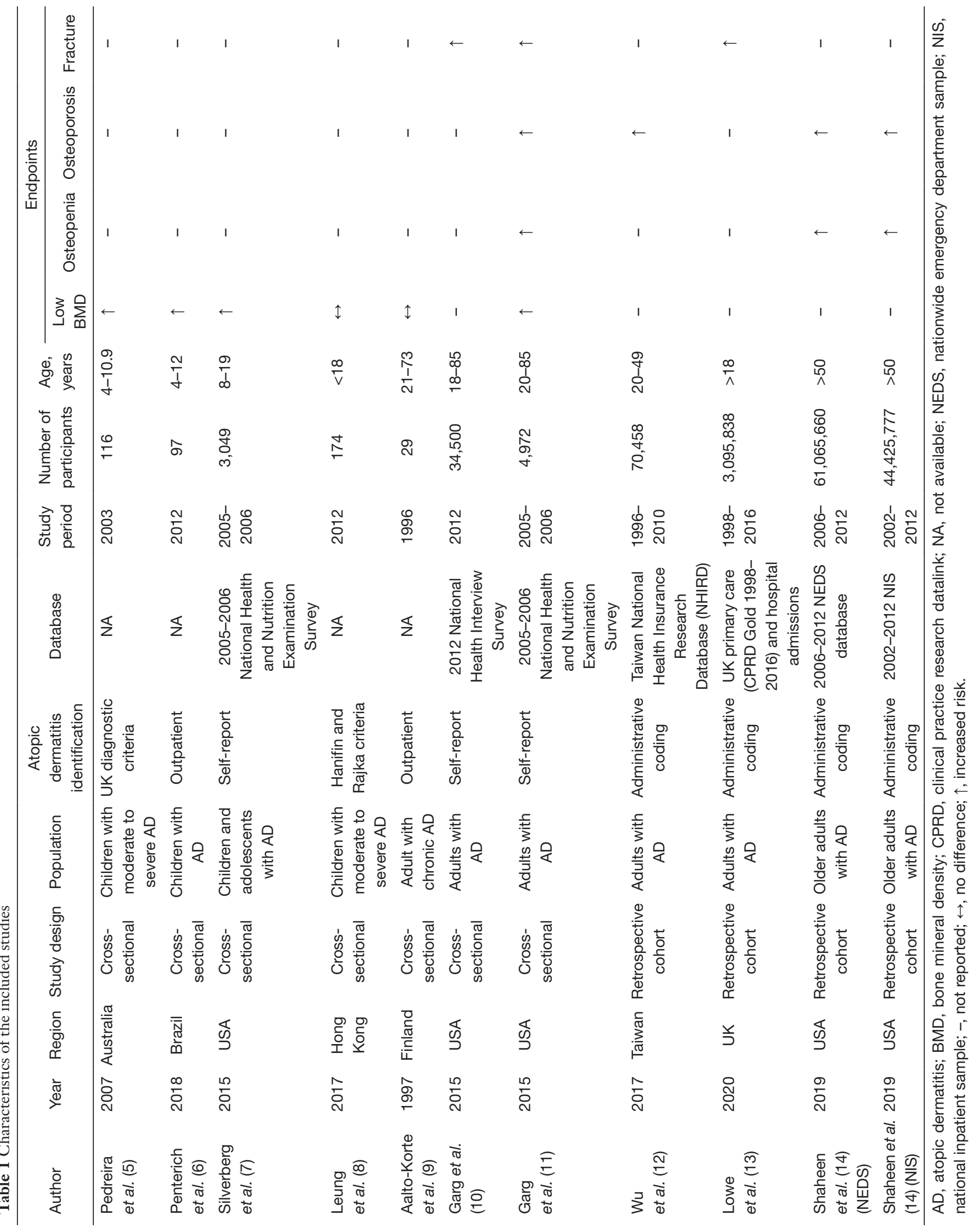




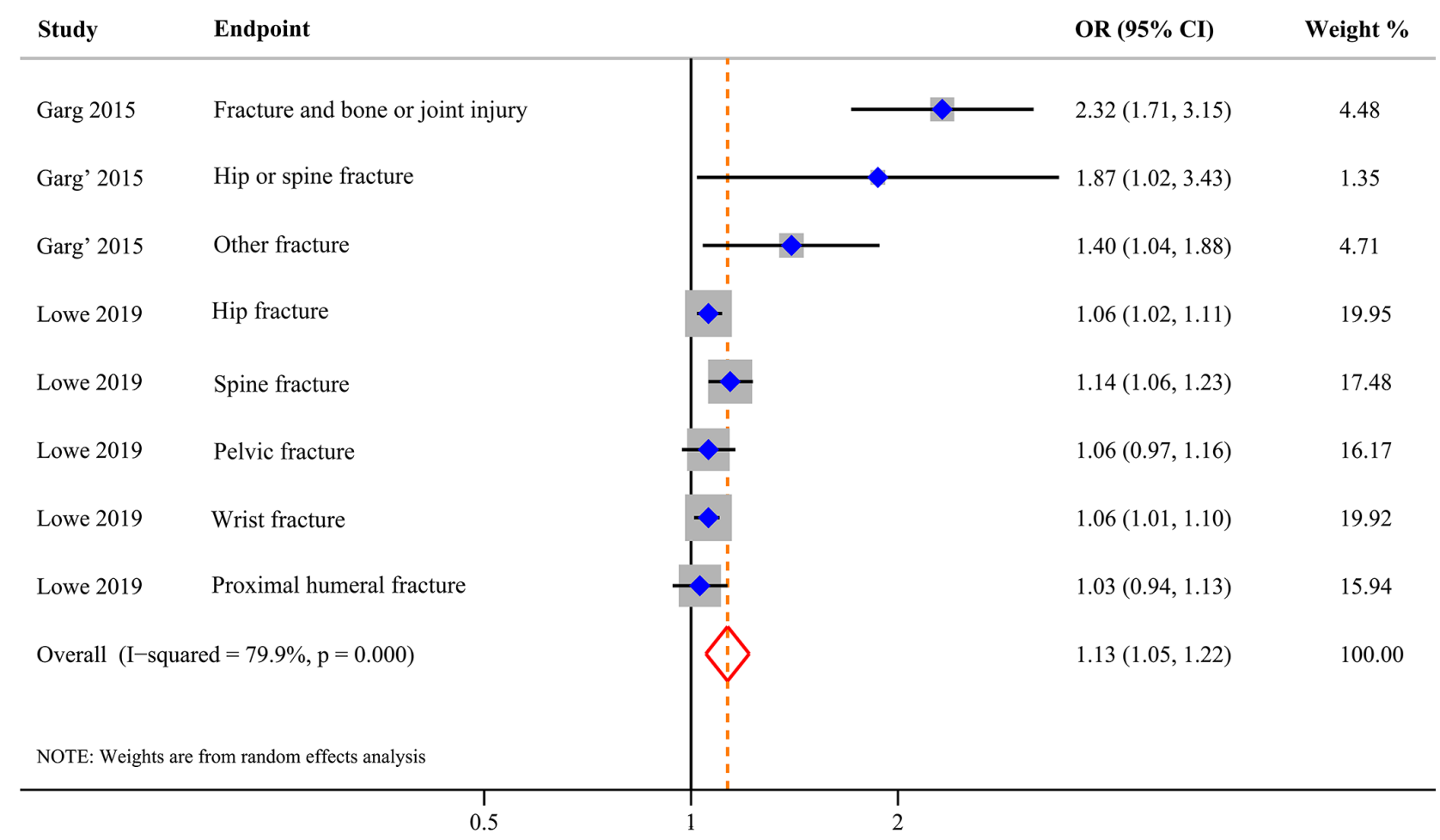

Figure 2 Forest plot showing the risk of fracture in patients with AD. CI, confidence interval; OR, odds ratio.

BMD, osteopenia, osteoporosis, and related fractures are multifactorial and complicated, which may not only relate to the disease pathogenesis but also close to the $\mathrm{AD}$ related pattern. In essence, $\mathrm{AD}$ is a kind of systematic chronic inflammatory diseases, just like inflammatory bowel disease, rheumatoid arthritis, and systemic lupus erythematosus (22). The relationship between chronic inflammatory diseases with bone loss and fracture risk has been well established (23-28). Inflammation-induced bone loss of these diseases was resulted from elevated numbers of bone-resorbing osteoclasts, which may help explain why the bone loss started as early as in children and adolescents $(29,30)$. There is also growing knowledge regarding the immune-mediated pathomechanism of $\mathrm{AD}$, and the osteoimmunology has highlighted the cross-regulation of bone and the immune system, which involving various cell types, signaling pathways, cytokines, and chemokines, under both homeostatic and pathogenic conditions (31-33). Since many cytokines and immune cell types have been found to be active in AD and play a role in bone remodeling, which may help to elaborate on how immuneassociated diseases affect osteoimmunology and lead to bone loss (32-38). Besides, a number of studies have found that Vitamin D deficiency is more prevalent in patients with $\mathrm{AD}$ and correlated with the severity of the disease, and extra supplementation of Vitamin D could result in a clinically meaningful AD severity reduction (39). As Vitamin D also increases intestinal calcium absorption and related to bone metabolism, it seems reasonable to expect that patients with AD have low BMD (40).

The AD-related pattern also plays an important role in bone metabolism on several fronts. (I) Corticosteroids can have profound, pluripotent effects on bone mineral turnover, particularly during developmental phases, but recent studies have demonstrated that topical corticosteroids have no effect on $\mathrm{BMD}$ in $\mathrm{AD}$ patients, yet, the accumulative effect could not be ruled out $(5,6,9,41)$. (II) $\mathrm{AD}$ patients are liable to food allergy and may have dietary restrictions, which could also lead to malnutrition and low BMD $(42,43)$. (III) AD patients are inclined to low levels of physical activity, which may contribute to decreased skeletal calcification and strength $(44,45)$. (IV) AD patients are vulnerable to depression, stress, anxiety, and sleep disturbance, all of which could further lead to low BMD and a higher risk of osteoporosis (46-49). (V) A growing body of evidence indicated that $\mathrm{AD}$ is also associated with 


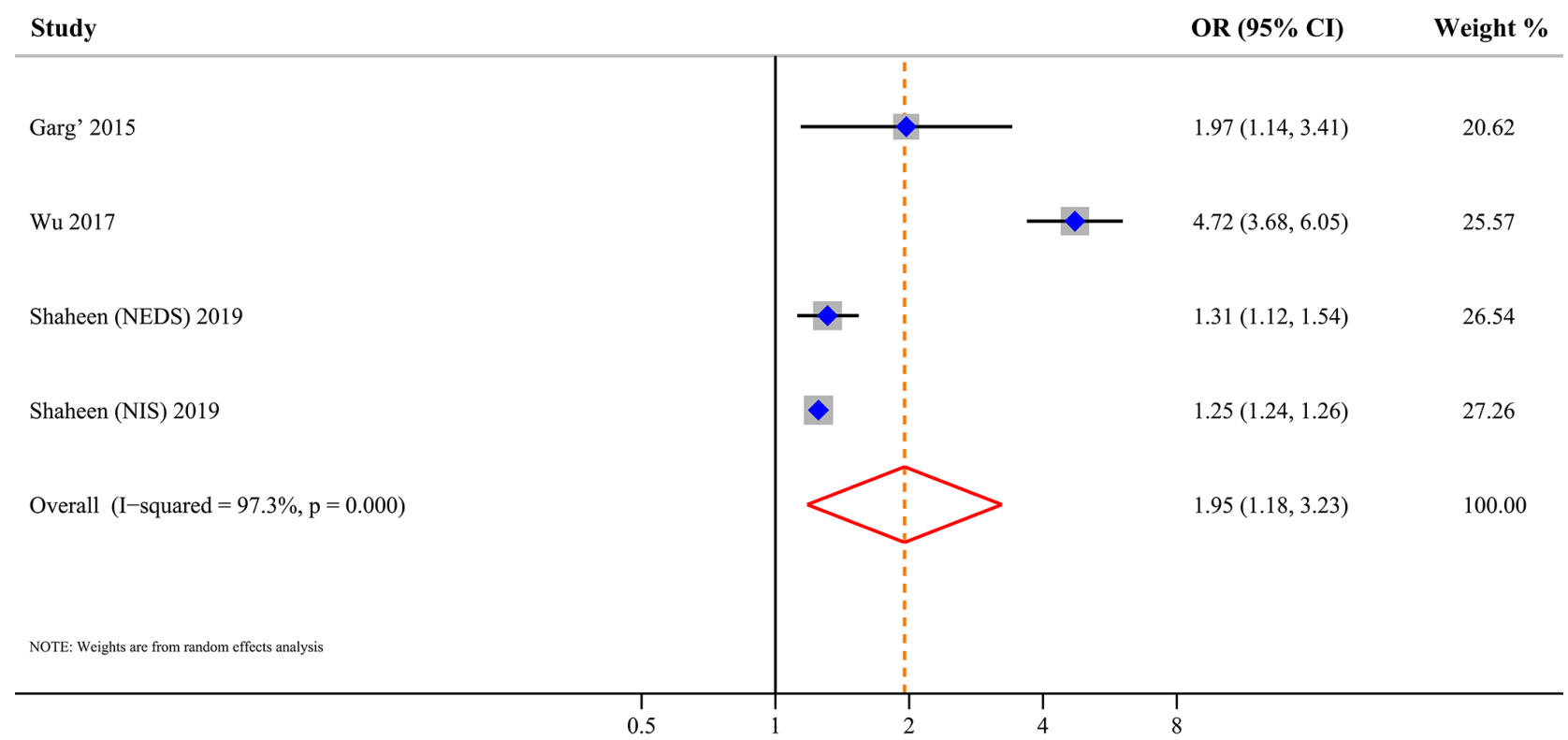

Figure 3 Forest plot showing the risk of osteoporosis in patients with AD. CI, confidence interval; OR, odds ratio.

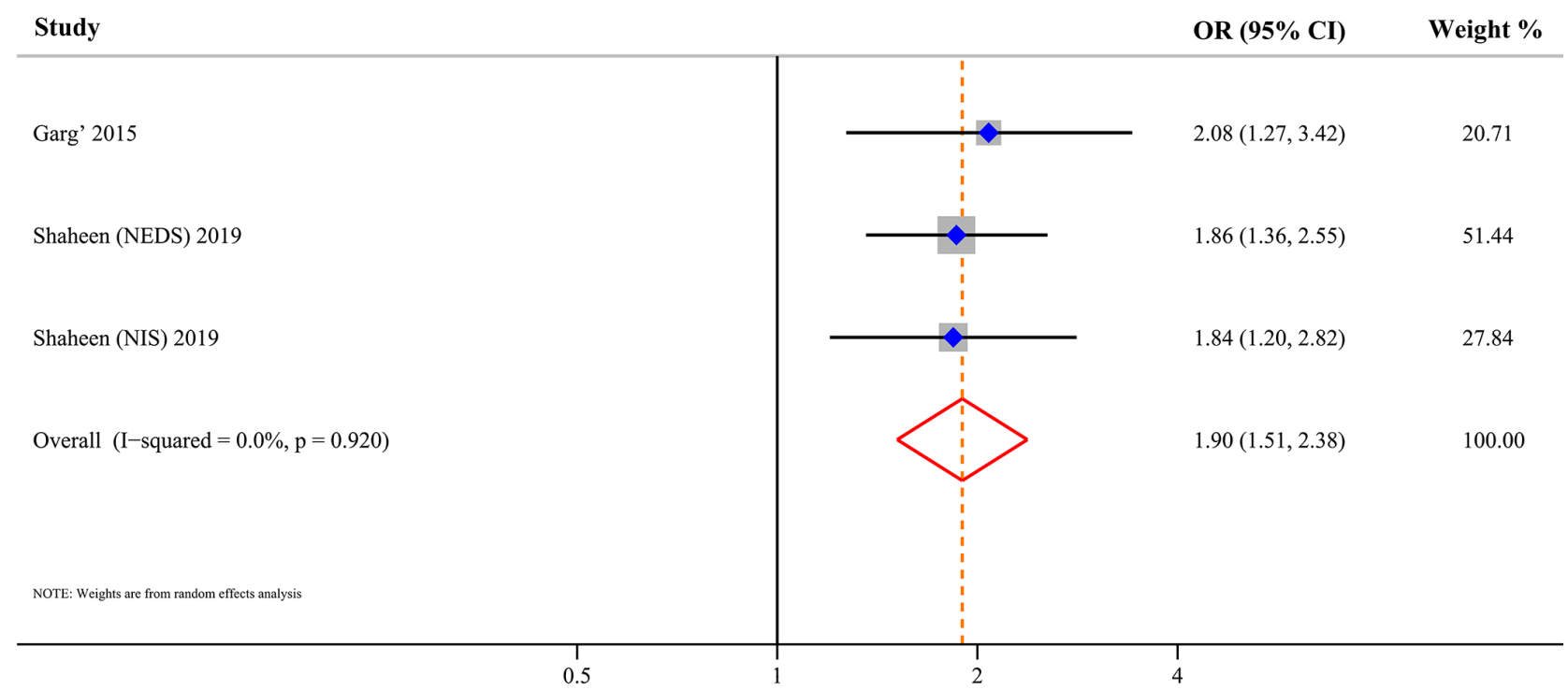

Figure 4 Forest plot showing the risk of osteopenia in patients with AD. CI, confidence interval; OR, odds ratio.

obesity, cardiovascular disease, and high alcohol and tobacco consumption, all of which are risk factors for bone loss and osteoporosis (50-53). (VI) Long-term sequelae of $\mathrm{AD}$ are essential to consider, and atopic march such as asthma is also associated with low BMD (54). These AD-related medical and behavioral factors, at least partially, explain the relationship between $\mathrm{AD}$ and bone loss.

\section{Implications for clinical practice}

So far, limited evidence suggested that the bone loss initiates as early as in children, although only a marginal decline in BMD. However, the difference in bone metabolism expands gradually with age and presents varied from osteopenia, osteoporosis, to related fractures. 
Previous epidemiological studies have demonstrated that the incidence of fractures in general populations increases steadily with age in females, and in males over 70 years old (55-57). Considering the female gender is a predisposing factor to $\mathrm{AD}$ (58-60), and females are at higher risk for osteoporosis and fractures than males, it is reasonable that the incidence of osteoporosis was higher in females than in males in both the $\mathrm{AD}$ cohort and non-AD cohort (12). However, there is varying evidence about the age modified fracture risk in patients with $\mathrm{AD}(10,12,13)$. Garg et al. reported that the prevalence of fracture among adults with $\mathrm{AD}$ increased gradually with age and peaked at ages 50 to 69 years, then decreased substantially after that (10). While Lowe et al. indicated that the fracture risk reached a plateau at ages 50 or older, the risks of hip fractures and wrist fractures decreased with age, the risk of spine fractures increased with age, and the risk of pelvic fractures peaked at ages 50 to 69 years and decreased thereafter (13). Based on the currently available evidence, different measures should be taken to alleviate the age-related effect of $\mathrm{AD}$ on fracture risk. For children, adolescents, and young adults, modify the AD-related patterns, including dietary, physical activity, psychological intervention, and improve their lifestyle, should be taken as a high priority. While for adults and older adults, early targeted screening of osteoporosis, and intervene early if necessary, would benefit individuals with $\mathrm{AD}$.

Furthermore, the standard therapy for patients with $\mathrm{AD}$ remains limited, which often have insufficient efficacy and causes many side effects. Therefore, other innovative alternative therapies with promising efficacy and acceptable safety should be considered $(61,62)$. The emerging biological therapeutics are focused on intervening in the inflammatory pathway by targeting specific molecules or their receptors, which may not only provide new prospects for the optimal treatment of $\mathrm{AD}$, but also prevent bone loss and fragility fractures induced by $\mathrm{AD}(63,64)$. Meanwhile, large prospective cohort studies are still needed to confirm these associations and identify potential risk factors. Additional research focus on determining the possible biological mechanisms linking AD to abnormal bone metabolism are also warranted.

\section{Limitations}

The main limitation of this study is the lack of highquality studies, which limited the assessment of abnormal bone metabolism, risk of osteopenia and osteoporosis, and related fractures in patients with $\mathrm{AD}$. Moreover, although studies have adjusted for major confounders, the results still could have been biased due to the retrospective nature, and the control for confounding variables was often not comprehensive. Besides, other factors, including data source, study population, $\mathrm{AD}$ diagnosis confirmation, and study design, could also affect the results.

\section{Conclusions}

In conclusion, compared with patients without $\mathrm{AD}$, patients with $\mathrm{AD}$ were associated with increased risks of low BMD, osteopenia, osteoporosis, and related fractures. To clarify the association between $\mathrm{AD}$ and abnormal bone metabolism, but also for better prevention and treatment of bone loss in patients with $\mathrm{AD}$, both clinical studies and basic research are warranted.

\section{Acknowledgments}

Funding: None.

\section{Footnote}

Reporting Checklist: The authors have completed the PRISMA reporting checklist. Available at http://dx.doi. org/10.21037/atm-20-4708

Conflicts of Interest: All authors have completed the ICMJE uniform disclosure form (available at http://dx.doi. org/10.21037/atm-20-4708). The authors have no conflicts of interest to declare.

Ethical Statement: The authors are accountable for all aspects of the work in ensuring that questions related to the accuracy or integrity of any part of the work are appropriately investigated and resolved. This systematic review and meta-analysis were based on previously published studies; thus, no ethical approval or patient consent is required.

Open Access Statement: This is an Open Access article distributed in accordance with the Creative Commons Attribution-NonCommercial-NoDerivs 4.0 International License (CC BY-NC-ND 4.0), which permits the noncommercial replication and distribution of the article with the strict proviso that no changes or edits are made and the original work is properly cited (including links to both the formal publication through the relevant DOI and the license). 
See: https://creativecommons.org/licenses/by-nc-nd/4.0/.

\section{References}

1. Williams H, Stewart A, von Mutius E, et al. Is eczema really on the increase worldwide? J Allergy Clin Immunol 2008;121:947-54.e15.

2. Odhiambo JA, Williams HC, Clayton TO, et al. Global variations in prevalence of eczema symptoms in children from ISAAC Phase Three. J Allergy Clin Immunol 2009;124:1251-8.e23.

3. de Mel S, Nordlind K, Holst M, et al. Polymorphisms in the serotonin transporter gene of patients with atopic dermatitis-association with personality traits related to high level of anxiety. Immunopharmacol Immunotoxicol 2012;34:534-8.

4. Silverberg JI, Hanifin JM. Adult eczema prevalence and associations with asthma and other health and demographic factors: A US population-based study. J Allergy Clin Immunol 2013;132:1132-8.

5. Pedreira CC, King E, Jones G, et al. Oral cyclosporin plus topical corticosteroid therapy diminishes bone mass in children with eczema. Pediatr Dermatol 2007;24:613-20.

6. Penterich V, Yang A, Pereira R, et al. Nutritional Status and Bone Metabolism in Children With Atopic Dermatitis. J Pediatr Endocrinol Metab 2018;31:247-60.

7. Silverberg JI. Association between childhood atopic dermatitis, malnutrition, and low bone mineral density: A US population-based study. Pediatr Allergy Immunol 2015;26:54-61.

8. Leung TF, Wang SS, Kwok FY, et al. Assessment of dietary food and nutrient intake and bone density in children with eczema. Hong Kong Med J 2017;23:470-9.

9. Aalto-Korte K, Turpeinen M. Bone mineral density in patients with atopic dermatitis. Br J Dermatol 1997;136:172-5.

10. Garg N, Silverberg JI. Association between eczema and increased fracture and bone or joint injury in adults: a US population-based study. JAMA Dermatol 2015;151:33-41.

11. Garg NK, Silverberg JI. Eczema is associated with osteoporosis and fractures in adults: a US populationbased study. J Allergy Clin Immunol 2015;135:1085-7.e2.

12. Wu CY, Lu YY, Lu CC, et al. Osteoporosis in adult patients with atopic dermatitis: A nationwide populationbased study. PLoS One 2017;12:e0171667.

13. Lowe KE, Mansfield KE, Delmestri A, et al. Atopic eczema and fracture risk in adults: A population-based cohort study. J Allergy Clin Immunol 2020;145:563-71.e8.
14. Shaheen MS, Silverberg JI. Atopic dermatitis is associated with osteoporosis and osteopenia in older adults. J Am Acad Dermatol 2019;80:550-1.

15. Higgins JP, Thomas J, Chandler J, et al. Cochrane handbook for systematic reviews of interventions. Chichester (UK): John Wiley \& Sons, 2019.

16. Moher D, Liberati A, Tetzlaff J, et al. Preferred reporting items for systematic reviews and meta-analyses: the PRISMA statement. Int J Surg 2010;8:336-41.

17. Peterson J, Welch V, Losos M, et al. The NewcastleOttawa scale (NOS) for assessing the quality of nonrandomised studies in meta-analyses. Ottawa: Ottawa Hospital Research Institute, 2011.

18. Zeng X, Zhang Y, Kwong JS, et al. The methodological quality assessment tools for preclinical and clinical studies, systematic review and meta-analysis, and clinical practice guideline: a systematic review. J Evid Based Med 2015;8:2-10.

19. Sanderson S, Tatt ID, Higgins J. Tools for assessing quality and susceptibility to bias in observational studies in epidemiology: a systematic review and annotated bibliography. Int J Epidemiol 2007;36:666-76.

20. Higgins JP, Altman DG, Gøtzsche PC, et al. The Cochrane Collaboration's tool for assessing risk of bias in randomised trials. BMJ 2011;343:d5928.

21. Egger M, Smith GD, Schneider M, et al. Bias in metaanalysis detected by a simple, graphical test. BMJ 1997;315:629-34.

22. Finlay AY. Quality of life in atopic dermatitis. J Am Acad Dermatol 2001;45:S64-6.

23. Xue AL, Wu SY, Jiang $\mathrm{L}$, et al. Bone fracture risk in patients with rheumatoid arthritis: a meta-analysis. Medicine 2017;96:e6983.

24. Szafors P, Che H, Barnetche T, et al. Risk of fracture and low bone mineral density in adults with inflammatory bowel diseases. A systematic literature review with metaanalysis. Osteoporos Int 2018;29:2389-97.

25. Xia J, Luo R, Guo S, et al. Prevalence and Risk Factors of Reduced Bone Mineral Density in Systemic Lupus Erythematosus Patients: A Meta-Analysis. Biomed Res Int 2019;2019:3731648.

26. Mendoza-Pinto C, Rojas-Villarraga A, Molano-Gonzalez $\mathrm{N}$, et al. Bone mineral density and vertebral fractures in patients with systemic lupus erythematosus: A systematic review and meta-regression. PLoS One 2018;13:e0196113.

27. Wu XD, Tian M, He Y, et al. Short to Midterm FollowUp of Periprosthetic Bone Mineral Density after Total Hip Arthroplasty with the Ribbed Anatomic Stem. Biomed 
Res Int 2019;2019:3085258.

28. Blavnsfeldt AG, de Thurah A, Thomsen MD, et al. The effect of glucocorticoids on bone mineral density in patients with rheumatoid arthritis: A systematic review and meta-analysis of randomized, controlled trials. Bone 2018;114:172-80

29. Jimi E, Aoki K, Saito H, et al. Selective inhibition of NFB blocks osteoclastogenesis and prevents inflammatory bone destruction in vivo. Nat Med 2004;10:617.

30. Eskan MA, Jotwani R, Abe T, et al. The leukocyte integrin antagonist Del-1 inhibits IL-17-mediated inflammatory bone loss. Nat Immunol 2012;13:465.

31. Walsh MC, Takegahara N, Kim H, Choi Y. Updating osteoimmunology: regulation of bone cells by innate and adaptive immunity. Nat Rev Rheumatol 2018;14:146-56.

32. Sirufo MM, De Pietro F, Bassino EM, et al. Osteoporosis in Skin Diseases. Int J Mol Sci 2020;21:4749.

33. Sirufo MM, Suppa M, Ginaldi L, et al. Does Allergy Break Bones? Osteoporosis and Its Connection to Allergy. Int J Mol Sci 2020;21:712.

34. Ginaldi L, De Martinis M, Ciccarelli F, et al. Increased levels of interleukin 31 (IL-31) in osteoporosis. BMC Immunol 2015;16:60.

35. Ginaldi L, De Martinis M, Saitta S, et al. Interleukin-33 serum levels in postmenopausal women with osteoporosis. Sci Rep 2019;9:3786.

36. Bodoor K, Al-Qarqaz F, Heis LA, et al. IL-33/13 Axis and IL-4/31 Axis Play Distinct Roles in Inflammatory Process and Itch in Psoriasis and Atopic Dermatitis. Clin Cosmet Investig Dermatol 2020;13:419-24.

37. De Martinis M, Sirufo MM, Suppa M, et al. IL-33/IL-31 Axis in Osteoporosis. Int J Mol Sci 2020;21:1239.

38. Topal FA, Zuberbier T, Makris MP, et al. The role of IL17, IL-23 and IL-31, IL-33 in allergic skin diseases. Curr Opin Allergy Clin Immunol 2020;20:367-73.

39. Sanna L, Stuart AL, Pasco JA, et al. Atopic disorders and depression: findings from a large, population-based study. J Affect Disord 2014;155:261-5.

40. Li YC, Pirro AE, Amling M, et al. Targeted ablation of the vitamin D receptor: an animal model of vitamin D-dependent rickets type II with alopecia. Proc Natl Acad Sci USA 1997;94:9831-5.

41. Loke YK, Gilbert D, Thavarajah M, et al. Bone mineral density and fracture risk with long-term use of inhaled corticosteroids in patients with asthma: systematic review and meta-analysis. BMJ Open 2015;5:e008554.

42. Hon KL, Leung TF, Kam WY, et al. Dietary restriction and supplementation in children with atopic eczema. Clin
Exp Dermatol 2006;31:187-91.

43. Bergmann MM, Caubet JC, Boguniewicz M, et al. Evaluation of food allergy in patients with atopic dermatitis. J Allergy Clin Immunol Pract 2013;1:22-8.

44. Strom MA, Silverberg JI. Associations of physical activity and sedentary behavior with atopic disease in United States children. J Pediatr 2016;174:247-53.e3.

45. Arkwright PD, Mughal MZ. Vertebral, pelvic, and hip fracture risk in adults with severe atopic dermatitis. J Allergy Clin Immunol 2020;145:487-8.

46. Xie Q-W, Xiaolu D, Tang X, et al. Risk of Mental Disorders in Children and Adolescents With Atopic Dermatitis: A Systematic Review and Meta-Analysis. Front Psychol 2019;10:1773.

47. Kim S, Lee JY, Oh JY, et al. The association between atopic dermatitis and depressive symptoms in Korean adults: the fifth Korea National Health and Nutrition Examination Survey, 2007-2012. Korean J Fam Med 2015;36:261.

48. Schonmann Y, Mansfield KE, Hayes JF, et al. Atopic eczema in adulthood and risk of depression and anxiety: a population-based cohort study. J Allergy Clin Immunol Pract 2020;8:248-57.e16.

49. Rønnstad ATM, Halling-Overgaard A-S, Hamann CR, et al. Association of atopic dermatitis with depression, anxiety, and suicidal ideation in children and adults: a systematic review and meta-analysis. J Am Acad Dermatol 2018;79:448-56.e30.

50. Zhang A, Silverberg JI. Association of atopic dermatitis with being overweight and obese: a systematic review and metaanalysis. J Am Acad Dermatol 2015;72:606-16.e4.

51. Silverberg JI, Greenland P. Eczema and cardiovascular risk factors in 2 US adult population studies. J Allergy Clin Immunol 2015;135:721-8.e6.

52. Kanis JA, Johansson H, Johnell O, et al. Alcohol intake as a risk factor for fracture. Osteoporos Int 2005;16:737-42.

53. Berg KM, Kunins HV, Jackson JL, et al. Association between alcohol consumption and both osteoporotic fracture and bone density. Am J Med 2008;121:406-18.

54. Bantz SK, Zhu Z, Zheng T. The atopic march: progression from atopic dermatitis to allergic rhinitis and asthma. J Clin Cell Immunol 2014;5:202.

55. van Staa TP, Dennison EM, Leufkens HG, et al. Epidemiology of fractures in England and Wales. Bone 2001;29:517-22.

56. Curtis EM, van der Velde R, Moon RJ, et al. Epidemiology of fractures in the United Kingdom 1988-2012: variation with age, sex, geography, ethnicity and socioeconomic 
status. Bone 2016;87:19-26.

57. Singer BR, McLauchlan GJ, Robinson CM, et al. Epidemiology of fractures in 15000 adults: the influence of age and gender. J Bone Joint Surg Br 1998;80:243-8.

58. Bryld LE, Hindsberger C, Kyvik KO, et al. Genetic factors in nickel allergy evaluated in a population-based female twin sample. J Invest Dermatol 2004;123:1025-9.

59. Modjtahedi BS, Modjtahedi SP, Maibach HI. The sex of the individual as a factor in allergic contact dermatitis. Contact Dermatitis 2004;50:53-9.

60. Noiesen E, Munk MD, Larsen K, et al. Gender differences in topical treatment of allergic contact dermatitis. Acta Derm Venereol 2009;89:79-81.

61. Sirufo MM, De Martinis M, Ginaldi L. Omalizumab an

Cite this article as: $\mathrm{Wu} \mathrm{D}, \mathrm{Wu} \mathrm{XD}$, Zhou X, Huang $\mathrm{W}$, Luo C, Liu Y. Bone mineral density, osteopenia, osteoporosis, and fracture risk in patients with atopic dermatitis: a systematic review and meta-analysis. Ann Transl Med 2021;9(1):40. doi: 10.21037/atm-20-4708 effective and safe alternative therapy in severe refractory atopic dermatitis: A case report. Medicine (Baltimore) 2018;97:e10897.

62. Wang D, Beck LA. Immunologic Targets in Atopic Dermatitis and Emerging Therapies: An Update. Am J Clin Dermatol 2016;17:425-43.

63. Chu CY. Treatments for Childhood Atopic Dermatitis: an Update on Emerging Therapies. Clin Rev Allergy Immunol 2020. [Epub ahead of print]. doi: 10.1007/ s12016-020-08799-1.

64. De Martinis M, Ginaldi L, Sirufo MM, et al. Alarmins in Osteoporosis, RAGE, IL-1, and IL-33 Pathways: A Literature Review. Medicina (Kaunas) 2020;56:138. 
Table S1 Details of the database search strategy (searched on: December 15, 2019)

\begin{tabular}{|c|c|c|}
\hline Search & Query & Results \\
\hline \multicolumn{3}{|c|}{ PubMed } \\
\hline$\# 1$ & "Dermatitis, Atopic"[Mesh] & 19,244 \\
\hline \#2 & Atopic dermatitis[Title/Abstract] & 19,937 \\
\hline \#3 & "Eczema"[Mesh] & 11,011 \\
\hline \#4 & Eczema[Title/Abstract] & 17,014 \\
\hline \#5 & \#1 OR \#2 OR \#3 OR \#4 & 41,880 \\
\hline \#6 & "Bone Density"[Mesh] & 51,908 \\
\hline \#7 & Bone mineral density[Title/Abstract] & 39,312 \\
\hline \#8 & "Bone Diseases, Metabolic"[Mesh] & 74,848 \\
\hline$\# 9$ & Osteopenia[Title/Abstract] & 9,298 \\
\hline$\# 10$ & "Osteoporosis"[Mesh] & 54,425 \\
\hline$\# 11$ & Osteoporosis[Title/Abstract] & 66,883 \\
\hline$\# 12$ & "Fractures, Bone"[Mesh] & 179,463 \\
\hline$\# 13$ & Fracture[Title/Abstract] & 167,622 \\
\hline \#14 & \#6 OR \#7 OR \#8 OR \#9 \#11 OR \#12 OR \#13 & 358,541 \\
\hline$\# 15$ & \#5 AND \#14 & 135 \\
\hline \multicolumn{3}{|c|}{ Cochrane } \\
\hline$\# 1$ & MeSH descriptor: [Dermatitis, Atopic] explode all trees & 1,650 \\
\hline \#2 & (Atopic dermatitis):ti,ab,kw & 4,211 \\
\hline \#3 & MeSH descriptor: [Eczema] explode all trees & 951 \\
\hline \#4 & (Eczema):ti,ab,kw & 3,545 \\
\hline \#5 & $\# 1$ or \#2 or \#3 or \#4 & 6,174 \\
\hline \#6 & MeSH descriptor: [Bone Density] explode all trees & 4,526 \\
\hline$\# 7$ & (Bone mineral density):ti,ab,kw & 8,041 \\
\hline \#8 & MeSH descriptor: [Bone Diseases, Metabolic] explode all trees & 4,329 \\
\hline \#9 & (Osteopenia):ti,ab,kw & 1,132 \\
\hline$\# 10$ & MeSH descriptor: [Osteoporosis] explode all trees & 3,824 \\
\hline$\# 11$ & (Osteoporosis):ti,ab,kw & 10,093 \\
\hline$\# 12$ & MeSH descriptor: [Fractures, Bone] explode all trees & 5,577 \\
\hline$\# 13$ & (Fracture):ti,ab,kw & 21,383 \\
\hline$\# 14$ & $\# 6$ or $\# 7$ or $\# 8$ or $\# 9$ or $\# 10$ or $\# 11$ or $\# 12$ or $\# 13$ & 31,074 \\
\hline$\# 15$ & $\# 5$ and \#14 & 51 \\
\hline \multicolumn{3}{|c|}{ Embase } \\
\hline$\# 1$ & 'atopic dermatitis'/exp & 43,424 \\
\hline \#2 & 'eczema'/exp & 33,908 \\
\hline \#3 & 'atopic dermatitis':ti,ab,kw & 32,821 \\
\hline$\# 4$ & eczema:ti,ab,kw & 29,957 \\
\hline \#5 & \#1 OR \#2 OR \#3 OR \#4 & 80,612 \\
\hline \#6 & 'bone density'/exp & 89,969 \\
\hline$\# 7$ & 'osteopenia'/exp & 18,656 \\
\hline \#8 & 'osteoporosis'/exp & 130,081 \\
\hline$\# 9$ & 'fracture'/exp & 330,981 \\
\hline$\# 10$ & 'bone mineral density':ti,ab,kw & 56,625 \\
\hline$\# 11$ & osteopenia:ti,ab,kw & 15,712 \\
\hline$\# 12$ & osteoporosis:ti,ab,kw & 110,324 \\
\hline$\# 13$ & fracture:ti,ab,kw & 220,411 \\
\hline \#14 & \#6 OR \#7 OR \#8 OR \#9 OR \#10 OR \#11 OR \#12 OR \#13 & 522,926 \\
\hline \#15 & \#5 AND \#14 & 923 \\
\hline
\end{tabular}


Table S2 Additional details of the included studies

\begin{tabular}{|c|c|c|c|c|c|c|c|}
\hline Endpoint & Author & Year & Region & Outcomes & Crude $H R / O R / \beta(95 \% \mathrm{Cl})$ & Multivariate OR/HR/adjusted $\beta$ (95\% Cl) & Covariates in a fully adjusted model \\
\hline \multirow[t]{10}{*}{ Fracture } & Garg et al. (11) & 2015 & USA & Any fracture & OR $1.49(1.12-1.96)$ & OR $1.48(1.10-1.99)$ & Not available \\
\hline & Lowe et al. (13) & 2019 & UK & Any fracture & HR $1.13(1.11-1.14)$ & HR $1.07(1.05-1.09)$ & $\begin{array}{l}\text { Age, sex, general practice, and date of cohort entry, time-updated asthma, index of multiple deprivations, calendar time, BMI, smoking status, } \\
\text { harmful alcohol use, oral glucocorticoid exposure }\end{array}$ \\
\hline & Garg et al. (10) & 2015 & USA & $\begin{array}{l}\text { Fracture and bone or joint } \\
\text { injury }\end{array}$ & - & OR $2.32(1.71-3.15)$ & $\begin{array}{l}\text { Age, sex, race/ethnicity, Hispanic origin, household income, highest level of household education, family structure, birthplace in the United } \\
\text { States, health insurance coverage }\end{array}$ \\
\hline & Garg et al. (11) & 2015 & USA & Hip or spine fracture & OR $1.80(1.00-3.24)$ & OR $1.87(1.02-3.43)$ & Not available \\
\hline & Lowe et al. (13) & 2019 & UK & Hip fractures & HR $1.11(1.07-1.16)$ & HR $1.06(1.02-1.11)$ & $\begin{array}{l}\text { Age, sex, race/ethnicity, Hispanic origin, household income, highest level of household education, family structure, birthplace in the United } \\
\text { States, health insurance coverage }\end{array}$ \\
\hline & Lowe et al. (13) & 2019 & UK & Spine fractures & HR $1.22(1.14-1.30)$ & HR $1.14(1.06-1.23)$ & $\begin{array}{l}\text { Age, sex, race/ethnicity, Hispanic origin, household income, highest level of household education, family structure, birthplace in the United } \\
\text { States, health insurance coverage }\end{array}$ \\
\hline & Lowe et al. (13) & 2019 & UK & Pelvic fractures & HR $1.12(1.04-1.21)$ & HR $1.06(0.97-1.16)$ & $\begin{array}{l}\text { Age, sex, race/ethnicity, Hispanic origin, household income, highest level of household education, family structure, birthplace in the United } \\
\text { States, health insurance coverage }\end{array}$ \\
\hline & Lowe et al. (13) & 2019 & UK & Wrist fractures & HR $1.09(1.05-1.13)$ & HR $1.06(1.01-1.10)$ & $\begin{array}{l}\text { Age, sex, race/ethnicity, Hispanic origin, household income, highest level of household education, family structure, birthplace in the United } \\
\text { States, health insurance coverage }\end{array}$ \\
\hline & Lowe et al. (13) & 2019 & UK & Proximal humeral fractures & HR $1.08(0.99-1.17)$ & HR $1.03(0.94-1.13)$ & $\begin{array}{l}\text { Age, sex, race/ethnicity, Hispanic origin, household income, highest level of household education, family structure, birthplace in the United } \\
\text { States, health insurance coverage }\end{array}$ \\
\hline & Garg et al. (11) & 2015 & USA & Other fracture & OR $1.42(1.07-1.89)$ & OR $1.40(1.04-1.88)$ & Not available \\
\hline \multirow[t]{4}{*}{ Osteoporosis } & $\begin{array}{l}\text { Shaheen et al. (14) } \\
\text { (NEDS) }\end{array}$ & 2019 & USA & Osteoporosis & - & OR $1.31(1.12-1.54)$ & Age, sex, race/ethnicity (white, nonwhite), insurance (private, government, self-pay, no charge, other), and household income quartile \\
\hline & $\begin{array}{l}\text { Shaheen et al. (14) } \\
\text { (NIS) }\end{array}$ & 2019 & USA & Osteoporosis & - & OR $1.25(1.24-1.26)$ & Age, sex, race/ethnicity (white, nonwhite), insurance (private, government, self-pay, no charge, other), and household income quartile \\
\hline & Wu et al. (12) & 2017 & Taiwan & Osteoporosis & HR $8.01(6.32-10.16)$ & HR $4.72(3.68-6.05)$ & $\begin{array}{l}\text { Age, sex, comorbidities (hypertension, diabetes mellitus, hyperlipidaemia, chronic kidney disease, chronic liver disease, chronic obstructive } \\
\text { pulmonary disease, depression), and use of systemic corticosteroids }\end{array}$ \\
\hline & Garg et al. (11) & 2015 & USA & Trochanter & OR $1.86(1.10-3.15)$ & OR $1.97(1.14-3.41)$ & Not available \\
\hline \multirow[t]{3}{*}{ Osteopenia } & $\begin{array}{l}\text { Shaheen et al. (14) } \\
\text { (NEDS) }\end{array}$ & 2019 & USA & Osteopenia & - & OR $1.86(1.36-2.55)$ & Age, sex, race/ethnicity (white, nonwhite), insurance (private, government, self-pay, no charge, other), and household income quartile \\
\hline & $\begin{array}{l}\text { Shaheen et al. (14) } \\
\text { (NIS) }\end{array}$ & 2019 & USA & Osteopenia & - & OR $1.84(1.20-2.82)$ & Age, sex, race/ethnicity (white, nonwhite), insurance (private, government, self-pay, no charge, other), and household income quartile \\
\hline & Garg et al. (11) & 2015 & USA & Trochanter & OR $2.03(1.24-3.33)$ & OR $2.08(1.27-3.42)$ & Not available \\
\hline \multirow{8}{*}{$\begin{array}{l}\text { Bone mineral } \\
\text { density }\end{array}$} & Garg et al. (11) & 2015 & USA & Total femur & $\beta-0.29(-0.49$ to -0.10$)$ & Adjusted $\beta-0.27(-0.46$ to -0.08$)$ & Not available \\
\hline & Silverberg et al. (7) & 2015 & USA & Total femur & $\beta-0.50(-0.80$ to -0.19$)$ & Adjusted $\beta-0.42(-0.68$ to -0.16$)$ & $\begin{array}{l}\text { Age, gender, race/ethnicity, household income, birthplace in the United States, the highest level of education in the household, body mass } \\
\text { index percentile (ordinal), and milk consumption in the past } 30 \text { days (binary) }\end{array}$ \\
\hline & Garg et al. (11) & 2015 & USA & Trochanter & $\beta-0.26(-0.43$ to -0.09$)$ & Adjusted $\beta-0.25(-0.42$ to -0.08$)$ & Not available \\
\hline & Silverberg et al. (7) & 2015 & USA & Trochanter & $\beta-0.31(-0.57$ to -0.05$)$ & Adjusted $\beta-0.29(-0.54$ to -0.05$)$ & $\begin{array}{l}\text { Age, gender, race/ethnicity, household income, birthplace in the United States, the highest level of education in the household, body mass } \\
\text { index percentile (ordinall), and milk consumption in the past } 30 \text { days (binary) }\end{array}$ \\
\hline & Garg et al. (11) & 2015 & USA & Femoral neck & $\beta-0.18(-0.37$ to 0.01$)$ & Adjusted $\beta-0.13$ (-0.31 to 0.04$)$ & Not available \\
\hline & Silverberg et al. (7) & 2015 & USA & Femoral neck & $\beta-0.31(-0.60$ to -0.02$)$ & Adjusted $\beta-0.29(-0.53$ to -0.05$)$ & $\begin{array}{l}\text { Age, gender, race/ethnicity, household income, birthplace in the United States, the highest level of education in the household, body mass } \\
\text { index percentile (ordinal), and milk consumption in the past } 30 \text { days (binary) }\end{array}$ \\
\hline & Garg et al. (11) & 2015 & USA & Total lumbar spine & $\beta-0.18(-0.37$ to 0.01$)$ & Adjusted $\beta-0.22(-0.41$ to -0.03$)$ & Not available \\
\hline & Silverberg et al. (7) & 2015 & USA & Total lumbar spine & $\beta-0.51(-0.86$ to -0.17$)$ & Adjusted $\beta-0.31(-0.52$ to -0.11$)$ & $\begin{array}{l}\text { Age, gender, race/ethnicity, household income, birthplace in the United States, the highest level of education in the household, body mass } \\
\text { index percentile (ordinall), nnd milk consumption in the past } 30 \text { days (binary) }\end{array}$ \\
\hline
\end{tabular}


Table S3 Methodological quality assessment (risk of bias) of included studies by Newcastle-Ottawa Scales (NOS)

\begin{tabular}{|c|c|c|c|c|c|c|c|c|c|}
\hline \multirow[b]{2}{*}{ Study } & \multicolumn{4}{|c|}{ Selection } & \multirow[b]{2}{*}{ Comparability } & \multicolumn{3}{|c|}{ Outcome } & \multirow[b]{2}{*}{ Total score } \\
\hline & Case definition & Representativeness & Control selection & Control definition & & $\begin{array}{l}\text { Assessment of } \\
\text { outcome }\end{array}$ & Length of follow-up & $\begin{array}{l}\text { Adequacy of follow- } \\
\text { up }\end{array}$ & \\
\hline Wu et al. (12), 2017 & * & * & * & * & ** & * & * & - & 8 \\
\hline Lowe et al. (13), 2019 & * & * & * & * & ** & * & * & - & 8 \\
\hline Shaheen et al. (14), 2019 (NEDS) & * & * & * & * & ** & * & - & - & 7 \\
\hline Shaheen et al. (14), 2019 (NIS) & * & * & * & * & ** & * & - & - & 7 \\
\hline
\end{tabular}

The asterisks represent a score, each asterisk represents one star.

Table S4 Quality assessment (risk of bias) of included studies by the Agency for Healthcare Research and Quality (AHRQ) checklist

\begin{tabular}{|c|c|c|c|c|c|c|c|}
\hline Item & $\begin{array}{l}\text { Pedreira et al. } \\
\text { (5), } 2007\end{array}$ & $\begin{array}{l}\text { Penterich } \\
\text { et al. (6), } 2012\end{array}$ & $\begin{array}{l}\text { Silverberg } \\
\text { et al. (7), } 2015\end{array}$ & $\begin{array}{l}\text { Leung } \\
\text { et al. (8), } 2017\end{array}$ & $\begin{array}{l}\text { Aalto-Korte } \\
\text { et al. (9), } 1997\end{array}$ & $\begin{array}{l}\text { Garg } \\
\text { et al. (10), } 2015\end{array}$ & $\begin{array}{l}\text { Garg et al. (11), } \\
\quad 2015\end{array}$ \\
\hline 1) Define the source of information (survey, record review) & $\mathrm{R}$ & $\mathrm{R}$ & $\mathrm{R}$ & $\mathrm{R}$ & $\mathrm{R}$ & $\mathrm{R}$ & $\mathrm{R}$ \\
\hline $\begin{array}{l}\text { 2) List inclusion and exclusion criteria for exposed and unexposed subjects (cases and controls) or refer } \\
\text { to previous publications }\end{array}$ & $\mathrm{R}$ & $\mathrm{u}$ & $\mathrm{R}$ & $\mathrm{R}$ & $\mathrm{R}$ & $\mathrm{R}$ & $\mathrm{R}$ \\
\hline 3) Indicate time period used for identifying patients & $\mathrm{R}$ & $u$ & $\mathrm{R}$ & $\mathrm{R}$ & Q & $\mathrm{R}$ & $\mathrm{R}$ \\
\hline 4) Indicate whether or not subjects were consecutive if not population-based & $\mathrm{u}$ & $\mathrm{u}$ & $\mathrm{R}$ & $\mathrm{u}$ & u & $\mathrm{R}$ & $\mathrm{R}$ \\
\hline $\begin{array}{l}\text { 5) Indicate if evaluators of subjective components of study were masked to other aspects of the status } \\
\text { of the participants }\end{array}$ & Q & Q & Q & Q & $\mathrm{u}$ & $\mathrm{R}$ & $\mathrm{R}$ \\
\hline $\begin{array}{l}\text { 6) Describe any assessments undertaken for quality assurance purposes (e.g., test/retest of primary } \\
\text { outcome measurements) }\end{array}$ & $\mathrm{R}$ & U & $\mathrm{R}$ & $\mathrm{R}$ & Q & $\mathrm{R}$ & $\mathrm{R}$ \\
\hline 7) Explain any patient exclusions from analysis & $\mathrm{R}$ & $\mathrm{u}$ & $\mathrm{R}$ & $\mathrm{R}$ & Q & $\mathrm{R}$ & $\mathrm{R}$ \\
\hline 8) Describe how confounding was assessed and/or controlled & Q & $u$ & $\mathrm{R}$ & $\mathrm{R}$ & $\mathrm{u}$ & $\mathrm{R}$ & $\mathrm{R}$ \\
\hline 9) If applicable, explain how missing data were handled in the analysis & Q & $\mathrm{u}$ & $\mathrm{R}$ & Q & $\mathrm{u}$ & $\mathrm{R}$ & $\mathrm{R}$ \\
\hline 10) Summarize patient response rates and completeness of data collection & Q & Q & $\mathrm{R}$ & Q & Q & $\mathrm{R}$ & Q \\
\hline $\begin{array}{l}\text { 11) Clarify what follow-up, if any, was expected and the percentage of patients for which incomplete } \\
\text { data or follow-up was obtained }\end{array}$ & Q & Q & Q & Q & Q & Q & Q \\
\hline
\end{tabular}

ARHQ methodology checklist for cross-sectional study (http://www.ncbi.nlm.nih.gov/books/NBK35156/). R, yes; Q, no; U, unclear. 